\title{
PET/CT Imaging of Chemokine Receptor CCR5 in Vascular Injury Model Using Targeted Nanoparticle
}

\author{
Hannah P. Luehmann*1, Eric D. Pressly*2 ${ }^{*}$ Lisa Detering ${ }^{1}$, Cynthia Wang ${ }^{2}$, Richard Pierce ${ }^{3}$, Pamela K. Woodard ${ }^{1}$, \\ Robert J. Gropler ${ }^{1}$, Craig J. Hawker ${ }^{2}$, and Yongjian Liu ${ }^{1}$ \\ ${ }^{I}$ Department of Radiology, Washington University, St. Louis, Missouri; ${ }^{2}$ Department of Materials, Chemistry and Biochemistry, \\ University of California Santa Barbara, California; and ${ }^{3}$ Department of Medicine, Washington University, St. Louis, Missouri
}

Inflammation plays important roles at all stages of atherosclerosis. Chemokine systems have major effects on the initiation and progression of atherosclerosis by controlling the trafficking of inflammatory cells in vivo through interaction with their receptors. Chemokine receptor 5 (CCR5) has been reported to be an active participant in the late stage of atherosclerosis and has the potential as a prognostic biomarker for plaque stability. However, its diagnostic potential has not yet been explored. The purpose of this study was to develop a targeted nanoparticle for sensitive and specific PET/CT imaging of the CCR5 receptor in an apolipoprotein $E$ knock-out $\left(\mathrm{ApoE}^{-/-}\right)$mouse vascular injury model. Methods: The D-Ala1-peptide T-amide (DAPTA) peptide was selected as a targeting ligand for the CCR5 receptor. Through controlled conjugation and polymerization, a biocompatible poly(methyl methacrylate)-core/polyethylene glycol-shell amphiphilic comblike nanoparticle was prepared and labeled with ${ }^{64} \mathrm{Cu}$ for CCR5 imaging in the $\mathrm{ApoE}^{-/-}$wire-injury model. Immunohistochemistry, histology, and real-time reverse transcription polymerase chain reaction (RT-PCR) were performed to assess the disease progression and upregulation of CCR5 receptor. Results: The ${ }^{64} \mathrm{Cu}$-DOTA-DAPTA tracer showed specific PET imaging of CCR5 in the $\mathrm{ApoE}^{-/-}$mice. The targeted ${ }^{64} \mathrm{Cu}$-DOTA-DAPTA-comb nanoparticles showed extended blood signal and optimized biodistribution. The tracer uptake analysis showed significantly higher accumulations at the injury lesions than those acquired from the sham-operated sites. The competitive PET receptor blocking studies confirmed the CCR5 receptor-specific uptake. The assessment of ${ }^{64} \mathrm{Cu}-\mathrm{DOTA}-\mathrm{DAPTA}-\mathrm{comb}$ in C57BL/6 mice and ${ }^{64} \mathrm{Cu}-\mathrm{DOTA}$-comb in $\mathrm{ApoE}^{-/-}$mice verified low nonspecific nanoparticle uptake. Histology, immunohistochemistry, and RT-PCR analyses verified the upregulation of CCR5 in the progressive atherosclerosis model. Conclusion: This work provides a nanoplatform for sensitive and specific detection of CCR5's physiologic functions in an animal atherosclerosis model.

Key Words: PET/CT; nanoparticles; chemokine receptor; atherosclerosis; CCR5

J Nucl Med 2014; 55:629-634

DOI: 10.2967/jnumed.113.132001

Received Aug. 31, 2013; revision accepted Dec. 16, 2013.

For correspondence or reprints contact: Yongjian Liu, Department of Radiology, Washington University, Campus Box 8225, 510 S. Kingshighway Blvd., St. Louis, MO 63110.

E-mail: liuyo@mir.wustl.edu

${ }^{*}$ Contributed equally to this work.

Published online Mar. 3, 2014.

COPYRIGHT (C 2014 by the Society of Nuclear Medicine and Molecular Imaging, Inc.
A therosclerosis, the leading cause of morbidity and mortality in Westernized societies, is a progressive disease characterized by the development of lipid-rich plaque lesions within vessel walls and extending into the vascular lumen. It is the underlying basis of cardiovascular diseases including myocardial infarction, stroke, and peripheral arterial disease (1). There are several phenotypes associated with the plaque such as inflammation and thin fibrous cap formation during the longitudinal progression of atherosclerosis. Currently, substantial evidence has demonstrated that atherosclerosis is essentially an inflammatory disease, for which inflammation has crucial roles in the initialization, progression, and eventual completion of vascular occlusion, which is the acute clinical event $(2,3)$. Therefore, inflammation specifically associated with the formation and progression of atherosclerotic plaque is an attractive research area for diagnosis of atherosclerosis, risk stratification of patients, and identification of novel therapeutic strategies (4-6).

Molecular imaging has become an important experimental tool for atherosclerosis research in the last decade. It can provide a direct entrance to the processes involved in the development of plaque and its complications at the molecular level to reveal disease diversity, guide specific therapy, and monitor treatment response $(7,8)$. Of various imaging modalities, the combined approach of PET/CT has been widely used because of its high sensitivity, quantitative diagnosis, and the potential for translation into patients (9).

During arterial inflammation, there is induction of expression of a variety of biomarkers such as vascular cell adhesion molecule-1, intercellular adhesion molecule-1, and E-selectin (10). Some molecular probes have been developed to image these biomarkers in preclinical atherosclerosis models with promising results. However, their translational potentials remain to be determined $(11,12)$. Although the clinical tracer ${ }^{18} \mathrm{~F}$-FDG has been widely used to evaluate the elevated metabolic activity in atherosclerosis, it is essentially a nonspecific tracer and has technical challenges to detect the lesions in coronary arteries because of the size of the vessel and myocardial uptake $(4,8,13)$.

Chemokines belong to a large family of structurally related and secretable, largely basic, chemotactic cytokines. They are expressed in an array of vascular cells such as endothelial cells and inflammatory cells within the atherosclerotic lesions and regulate leukocyte activation and recruitment to sites of inflammation via interaction with a family of G-protein-coupled receptors $(14,15)$. Recent studies have reported upregulation of chemokine receptors (CRs) on the inflammatory cells identified in human 
plaque samples. In murine transgenic and knock-out atherosclerosis models, the important roles of several CCRs, including CCR5, CCR2, and CX3CR1, by affecting leukocyte subset recruitment have already been well defined $(16,17)$. During the progression of atherosclerotic lesions, CCR5 was selectively upregulated in certain subsets of monocytes and played critical roles in mediating their entry into plaques (18), especially in the late stage of the disease (19-21), making it an important biomarker to study the plaque development, progression, and stability by tracking these inflammatory cells. Previously, we have imaged the expression of $8 \mathrm{CRs}$, including the CCR5, in an apolipoprotein E knock-out (ApoE ${ }^{-1-}$ ) mouse vascular injury model with PET/CT (22). In this study, we prepared a CCR5 receptor-specific probe through the conjugation of targeting peptide $\mathrm{D}$ - $\mathrm{Ala}_{1}$-peptide T-amide (DAPTA) $(23,24)$ on a comblike nanoparticle $(25,26)$ for in vivo PET/CT imaging of CCR5 receptor upregulation in the same model. The CCR5 receptor-targeting specificity and imaging efficiency were compared with the control nanoparticles and the DAPTA peptide tracer alone. This work may provide a nanoplatform for sensitive and specific detection of the CCR5's physiologic functions in animal atherosclerosis models.

\section{MATERIALS AND METHODS}

Materials were purchased from Sigma-Aldrich and used without further purification unless otherwise stated. The ${ }^{64} \mathrm{Cu}$ (half-life $=12.7 \mathrm{~h}$, $\beta^{+}=17 \%, \beta^{-}=40 \%$ ) was produced at the Washington University cyclotron facility (27). Functionalized poly(ethyleneglycol) (PEG) derivatives were obtained from Intezyne Technologies. Tris-t-butylester-DOTA, 1,4,7,10-tetraazacyclododecane, and DOTA- $N$-hydroxysuccinimide ester were purchased from Macrocyclics. D-Ala A $_{1}$-peptide T-amide (DAPTA, D-A 1 STTTNYT-NH2) was customized by CPC Scientific. Centricon tubes were purchased from Millipore. Zeba desalting spin columns were from Pierce. Reversed-phase high-performance liquid chromatography was performed on a system equipped with a UV/VIS detector (Dionex) and a radioisotope detector (B-FC3200; BioScan Inc.) on a C-18 analytic column (5 mm, 4.6 $\times 220 \mathrm{~mm}$; Perkin Elmer). Polymeric materials were characterized by ${ }^{1} \mathrm{H}$ and ${ }^{13} \mathrm{C}$ nuclear MR (NMR) spectroscopy using a Bruker 500-MHz spectrometer with the residual solvent signal as an internal reference. Gel permeation chromatography was performed in dimethylformamide on a Waters system equipped with four $5-\mu \mathrm{m}$ Waters columns $(300 \times$ $7.7 \mathrm{~mm})$ connected in series with increasing pore size $\left(10^{2}, 10^{3}, 10^{4}\right.$, and $10^{6} \AA$ ) and Waters 410 differential refractometer index and 996 photodiode array detectors. The molecular weights of the polymers were calculated relative to linear polymethyl methacrylate (PMMA) or PEG standards. Infrared spectra were recorded on a Perkin Elmer Spectrum 100 with a Universal ATR sampling accessory. The synthesis and characterization of DOTA-DAPTA, DOTA-comb, and DOTADAPTA-comb (Supplemental Figs. 1 and 2) are described in the supplemental materials (available at http://jnm.snmjournals.org).

\section{Mouse Vascular Injury Model}

All animal studies were performed in compliance with guidelines set forth by the National Institutes of Health Office of Laboratory Animal Welfare and approved by the Washington University Animal Studies Committee. The mouse vascular injury model was induced in ApoE ${ }^{-1-}$ mice $(n=25$, Taconic Inc.) through wire injury on the right femoral artery as described previously $(22,28,29)$. The left femoral artery was also surgically prepared by undergoing incision and closure without guide wire endothelial injury to serve as the sham site. Wildtype C57BL/6 mice $(n=5)$ fed with normal chow underwent the same wire-injury procedure and were used as control animals.

\section{Biodistribution Studies}

${ }^{64} \mathrm{Cu}$-DOTA-DAPTA-comb and ${ }^{64} \mathrm{Cu}$-DOTA-comb were reconstituted in $0.9 \%$ sodium chloride (APP Pharmaceuticals) for intravenous injection. Male C57BL/6 mice weighing 20-25 g ( $n=4$ /group) were anesthetized with inhaled isoflurane, and approximately $370 \mathrm{kBq}$ of labeled nanoparticles $(7.2-9.0 \mu \mathrm{g} / \mathrm{kg}$ of body weight) or the DOTADAPTA peptide $(0.35-0.44 \mu \mathrm{g} / \mathrm{kg}$ of body weight) in $100 \mu \mathrm{L}$ of saline were injected via the tail vein. The mice were reanesthetized before they were euthanized by cervical dislocation at each time point $(1,24$, and $48 \mathrm{~h}$ ) after injection. Organs of interest were collected, weighed, and counted in a well $\gamma$ counter (Beckman 8000). Standards were prepared and measured along with the samples to calculate the percentage injected dose per gram of tissue (\%ID/g) (27).

\section{Small-Animal PET/CT Imaging}

Two weeks after the wire injury, small-animal PET/CT imaging was performed on $\mathrm{ApoE}^{-1-}$ mice to determine the uptake and progression at atheroscleroticlike lesions. The injured control C57BL/6 mice $(n=5)$ were scanned following the same protocol. For PET/CT imaging, mice were injected with ${ }^{64} \mathrm{Cu}$-DOTA-DAPTA $(1.85-3.7 \mathrm{MBq}$ in $100 \mu \mathrm{L}$ of saline), and 0- to 60-min dynamic scans were acquired on the smallanimal PET Focus-220 or Inveon PET/CT system (Siemens). For ${ }^{64} \mathrm{Cu}-$ DOTA-DAPTA-comb and ${ }^{64} \mathrm{Cu}$-DOTA-comb, 3.7 MBq in $100 \mu \mathrm{L}$ of saline were injected via tail vein. The imaging sessions were collected on the PET scanners at 1, 4, 24, and $48 \mathrm{~h}$ after injection. Both PET scanners were cross-calibrated periodically. Data analysis of the PET images was performed using the manufacturer's software (ASI Pro or IRW; Siemens). The accumulation of the PET tracers at the injury site and on the contralateral sham-operated femoral artery was calculated as $\% \mathrm{ID} / \mathrm{g}$ from the maximum-intensity-projection images. After the last PET/CT scan, the animals were euthanized by cervical dislocation, and the femoral vessels were either perfusion-fixed in situ with freshly prepared $4 \%$ paraformaldehyde in $1 \times$ phosphate-buffered saline for histopathology and immunohistochemistry or fast-frozen for real-time reverse transcription polymerase chain reaction (RT-PCR) analysis. Competitive receptor blocking studies were performed on $\mathrm{ApoE}^{-1-}$ mice with wire injuries for ${ }^{64} \mathrm{Cu}$-DOTA-DAPTA-comb by coinjection of unlabeled DOTA-DAPTA-comb in 100-fold excess $(n=6)$ at $2 \mathrm{wk}$ after the wire injury, followed by PET scans at 1,24 , and $48 \mathrm{~h}$ after injection.

\section{Immunohistochemistry, Histologic Characterization, and RT-PCR Assay}

Serial sections (5- $\mu \mathrm{m}$ thick) were cut from paraformaldehyde-fixed (24 h), paraffin-embedded specimens. The sections were deparaffinized and rehydrated through a series of xylenes and graded alcohols before undergoing antigen retrieval pretreatment (10 mM Tris, $1 \mathrm{mM}$ ethylenediaminetetraacetic acid, $0.05 \%$ polysorbate, $\mathrm{pH} 9.0$, for $10 \mathrm{~min}$ ). They were treated with $0.3 \% \mathrm{H}_{2} \mathrm{O}_{2}$ for $30 \mathrm{~min}$, followed by blocking serum for $1 \mathrm{~h}$ to prevent nonspecific binding (Vectastain; Vector Laboratories). The sections were then incubated overnight at $4^{\circ} \mathrm{C}$ with primary antibody (anti-CCR5, 1:200 in blocking serum; Abcam). Secondary antibody was applied (Vector Laboratories), and color development was achieved through horseradish peroxidase-DAB (3,3'-diaminobenzidine tetrahydrochloride) (brown)-based immunostaining kits (Vector Laboratories). Sections were counterstained with tartrazine (yellow). Digital images of the stained sections were obtained using a scanning light microscope (NanoZoomer; Hamamatsu). Additionally, hematoxylin and eosin (H\&E) staining was also performed on the consecutively cut specimens.

Tissue RNA was isolated using TRIzol (Invitrogen) per the manufacturer's instruction. RNA isolated from injured and sham femoral arteries was used for real-time RT-PCR. Reverse transcription 
reactions used $1 \mu \mathrm{g}$ of total RNA, random hexamer priming, and Superscript II reverse transcriptase (Invitrogen). The expressions of CCR5 and glyceraldehyde 3-phosphate dehydrogenase (GAPDH) were determined using Taqman assays (Invitrogen) and an EcoTM Real-Time PCR System (Illumina) in duplicate in 48-well plates. PCR cycling conditions were as follows: $50^{\circ} \mathrm{C}$ for $2 \mathrm{~min}, 95^{\circ} \mathrm{C}$ for $21 \mathrm{~s}$, and $60^{\circ} \mathrm{C}$ for $20 \mathrm{~s}$. GAPDH expression was used as a comparator with $\Delta \Delta \mathrm{C}_{\mathrm{t}}$ calculations.

\section{Statistical Analysis}

Group variation is described as mean $\pm \mathrm{SD}$. Groups were compared using 1-way ANOVA with a Bonferroni adjustment. Individual group differences were determined using a 2-tailed Mann-Whitney test. The significance level in all tests was a $P$ value of 0.05 or less.

\section{RESULTS}

\section{Biodistribution of ${ }^{64} \mathrm{Cu}$-DOTA-DAPTA-Comb}

Biodistribution of ${ }^{64} \mathrm{Cu}$-DOTA-comb was previously reported, with most activity accumulated in the mononuclear phagocyte system (liver and spleen) (27). Interestingly, the targeted ${ }^{64} \mathrm{Cu}-$ DOTA-DAPTA-comb showed a much improved organ distribution profile. At $1 \mathrm{~h}$ after injection, the blood signal of ${ }^{64} \mathrm{Cu}$-DOTADAPTA-comb $(33.6 \pm 7.05 \% \mathrm{ID} / \mathrm{g}, n=6)$ was slightly higher than that of ${ }^{64} \mathrm{Cu}$-DOTA-comb $(25.4 \pm 3.04 \% \mathrm{ID} / \mathrm{g}, n=6)$ previously reported (Fig. 1) (27). However, its liver and spleen accumulations were both 7 times less (liver, $5.24 \pm 1.13 \% \mathrm{ID} / \mathrm{g}$ vs. $41.9 \pm 7.54 \% \mathrm{ID} / \mathrm{g}$; spleen, $3.10 \pm 0.55 \% \mathrm{ID} / \mathrm{g}$ vs. $25.4 \pm 2.48$ $\% \mathrm{ID} / \mathrm{g})$. At $24 \mathrm{~h}$ after injection, in contrast to the fast clearance of ${ }^{64} \mathrm{Cu}$-DOTA-comb from systemic circulation, only one third of ${ }^{64} \mathrm{Cu}$-DOTA-DAPTA-comb was removed from the blood, which led to twice as much $(P<0.001, n=4)$ retained in the blood-pool organs. A further study showed that even at $48 \mathrm{~h}$ after injection, there was still about half of the initial retention in the blood $(15.1 \pm 1.70 \% \mathrm{ID} / \mathrm{g})$. During the 48 -h period, the renal and gastrointestinal tract clearance remained constant, albeit the hepatic and splenic accumulations increased over time, yet both were about $10 \% \mathrm{ID} / \mathrm{g}$ at the end of this study.

\section{PET/CT Imaging}

PET/CT imaging with ${ }^{64} \mathrm{Cu}$-DOTA-DAPTA in the $\mathrm{ApoE}^{-1-}$ model $(n=6)$ at $2 \mathrm{wk}$ after wire injury showed a typical peptide tracer profile with fast renal clearance (Fig. 2A). The summed 0to 60-min dynamic PET/CT image showed tracer accumulation at the injury lesion, with little uptake observed around the sham site.

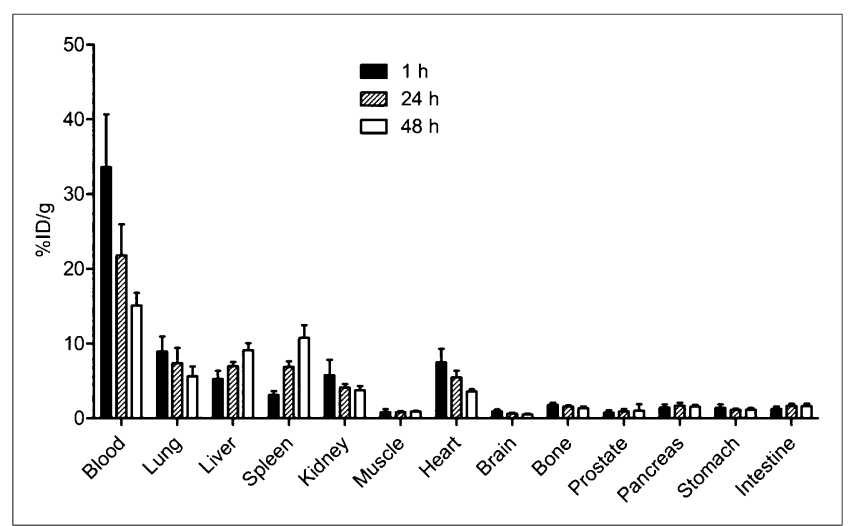

FIGURE 1. Biodistribution of ${ }^{64} \mathrm{Cu}-\mathrm{DOTA}-\mathrm{DAPTA}-\mathrm{comb}$ in $\mathrm{C} 57 \mathrm{BL} / 6$ mice $(n=4$ /group).

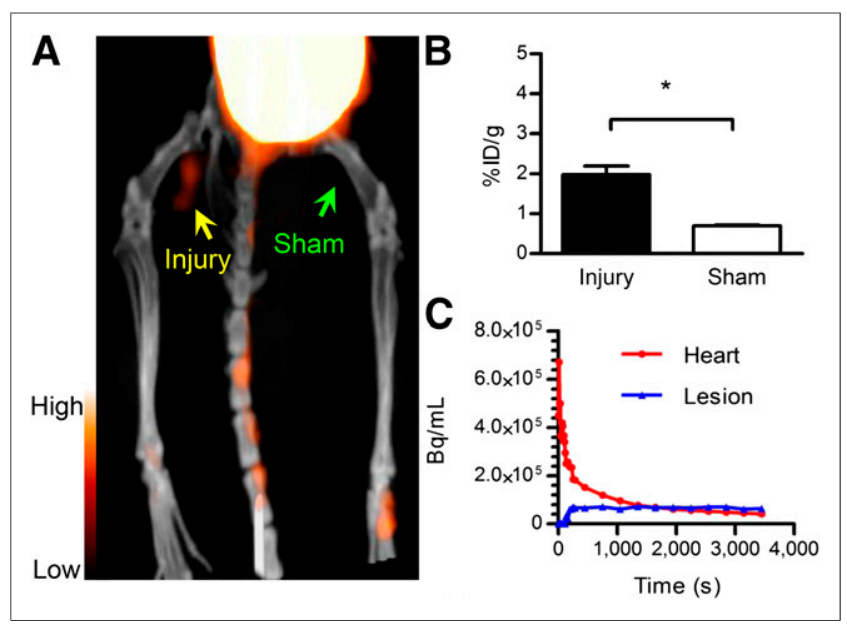

FIGURE 2. PET/CT image of ${ }^{64} \mathrm{Cu}$-DOTA-DAPTA in wire-injury-induced $\mathrm{ApoE}^{-/-}$mouse atherosclerosis model at $2 \mathrm{wk}$ after injury. (A) Maximumintensity-projection image showing accumulation of ${ }^{64} \mathrm{Cu}$-DOTA-DAPTA at injured lesion. (B) Uptake analysis of ${ }^{64} \mathrm{Cu}$-DOTA-DAPTA at injured and sham-operated sites. (C) Time-activity curves of ${ }^{64} \mathrm{Cu}$-DOTA-DAPTA at heart and lesion. ${ }^{*} P<0.05, n=6$.

The quantitative analysis demonstrated almost 2-fold-higher uptake at the injury sites $(1.97 \pm 0.22 \% \mathrm{ID} / \mathrm{g}, P<0.001, n=6)$ than that obtained from the contralateral thigh $(0.69 \pm 0.02 \% \mathrm{ID} / \mathrm{g}$, $n=6$ ) (Fig. 2B). Dynamic analysis of tracer uptake at the injury lesion showed stable accumulation during the study whereas ${ }^{64} \mathrm{Cu}-$ DOTA-DAPTA quickly cleared from the blood pool (Fig. 2C).

The targeted ${ }^{64} \mathrm{Cu}$-DOTA-DAPTA-comb showed rapid accumulation around the injury site and weak uptake at sham site at $1 \mathrm{~h}$ after injection (Fig. 3A). Quantitative analysis showed gradually increased tracer uptake at the injured femoral artery from $3.41 \pm$ $0.40 \% \mathrm{ID} / \mathrm{g}(n=6)$ at $1 \mathrm{~h}$ after injection to $5.55 \pm 1.13 \% \mathrm{ID} / \mathrm{g}$ at $24 \mathrm{~h}$ after injection, which then plateaued until $48 \mathrm{~h}$ (Fig. 3B). In contrast, the tracer uptake at the sham site hardly changed during the 48 -h period $(1.14 \pm 0.32$ to $1.50 \pm 0.21 \% \mathrm{ID} / \mathrm{g}, n=6)$, leading to an increased injury-to-sham uptake ratio from $3.00 \pm$ 0.92 at $1 \mathrm{~h}$ to $4.36 \pm 1.11$ at the end of the study. Compared with the data obtained with ${ }^{64} \mathrm{Cu}$-DOTA-DAPTA, the ${ }^{64} \mathrm{Cu}$-DOTADAPTA-comb illustrated a significantly $(P<0.0005, n=6)$ higher uptake at the injury lesion and contrast ratio.

Further, the nonspecific accumulation of ${ }^{64} \mathrm{Cu}$-DOTA-DAPTAcomb was also assessed in wire-injured C57BL/6 control mice. As shown in Figure 4A, the representative PET/CT image at $24 \mathrm{~h}$ showed minimum uptake around the injury site. The uptake analysis showed similar tracer accumulation at both injury and sham sites, with no significant difference during the study (Fig. 4B). Further, the control nanoparticle of ${ }^{64} \mathrm{Cu}$-DOTA-comb was also evaluated in the $\mathrm{ApoE}^{-/-}$mice for nonspecific accumulation, with little uptake observed at both injury and sham sites (Fig. 4A). The uptake analysis demonstrated significantly $(P<0.001, n=6)$ lower accumulation at the injury lesion than those obtained with targeted ${ }^{64} \mathrm{Cu}$-DOTA-DAPTA-comb (Fig. 4B).

The competitive receptor blocking with the coinjection of unlabeled DOTA-DAPTA-comb at 2 wk after injury resulted in a substantial decrease of tracer uptake at the injury site to a level similar to those obtained at the control site on the representative PET/CT images (Fig. 4A). The quantitative analysis showed that the uptake at the injury lesion had decreased to $1.81 \pm 0.10,1.92$ \pm 0.22 , and $1.78 \pm 0.27 \% \mathrm{ID} / \mathrm{g}$ at 1,24 , and $48 \mathrm{~h}$, respectively, all 


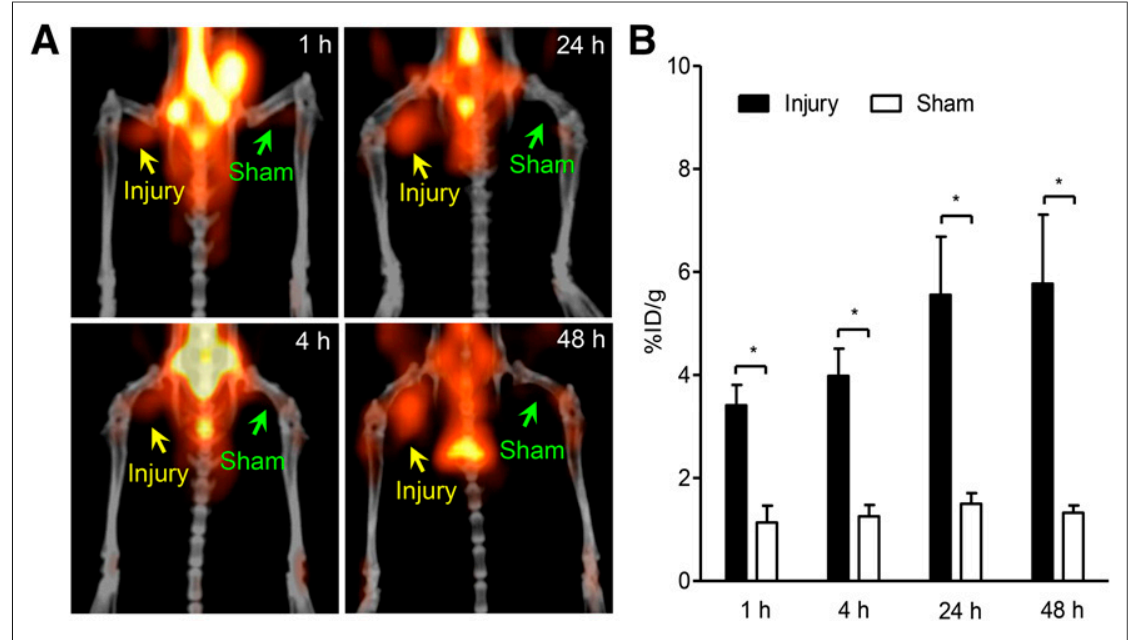

FIGURE 3. PET/CT images of ${ }^{64} \mathrm{Cu}-\mathrm{DOTA}-\mathrm{DAPTA}-\mathrm{comb}$ in wire-injury-induced $\mathrm{ApoE}^{-/-}$mouse atherosclerosis model at $2 \mathrm{wk}$ after injury. (A) Maximum-intensity-projection images showing accumulation of ${ }^{64} \mathrm{Cu}$-DOTA-DAPTA-comb at injured lesion at various time points. (B) Uptake analysis of ${ }^{64} \mathrm{Cu}$-DOTA-DAPTA-comb at injured and sham-operated sites. ${ }^{*} P<0.05, n=6$.

significantly $(P<0.001, n=6)$ lower than those obtained in the nonblocking studies (Figs. 3A and 4B). The injury-to-sham uptake ratios were also significantly reduced $(1.18 \pm 0.19$ to $1.35 \pm 0.47$, $P<0.005, n=6$ ) to a level similar to the results obtained with control ${ }^{64} \mathrm{Cu}$-DOTA-comb at the injury lesion.

\section{Histology, Immunohistochemistry, and RT-PCR}

The H\&E staining of right femoral arteries harvested from the $\mathrm{ApoE}^{-1-}$ mice at $2 \mathrm{wk}$ after injury showed significantly progressive atherosclerotic plaque in contrast to the intact vasculature of the sham-operated left femoral artery (Fig. 5). The DAB staining of CCR5 expression on the injury artery was found throughout the injured vessel wall, especially in the medial layer to the thickened neointima that resulted from the wire injury (Fig. 5). On the sham tissue, the vessel wall was much thinner than the injured counterpart and showed significantly less presence of the CCR5 receptor. The quantitative RT-PCR data from the tissue collected at 2 wk after injury demonstrated increased expression of CCR5 RNA on the injured lesion relative to the sham site. The injury-to-sham ratio of RNA expression was $3.91 \pm 1.36(n=5)$.

\section{DISCUSSION}

We report here the results for PET/CT imaging of CCR5 receptor upregulation associated with wire-injury-induced atherosclerosis in $\mathrm{ApoE}^{-1-}$ mice. The presence of the CCR5 receptor was identified with ${ }^{64} \mathrm{Cu}$-DOTA-DAPTA-comb nanoparticles using PET/CT, and immunohistochemistry and RT-PCR in the progressive ApoE $^{-/-}$model. The imaging capability and superiority of the targeted ${ }^{64} \mathrm{Cu}$-DOTA-DAPTA-comb nanoparticle over the ${ }^{64} \mathrm{Cu}$-DOTA-DAPTA peptide tracer for CCR5 receptor molecular imaging were demonstrated.

It is becoming increasingly clear that many chemokines and their receptors play a role in the development of atherosclerosis, especially for CCR2, CX3CR1, and CCR5 (30). Although there may be some overlap among the functions of these chemokine systems during the development of atherosclerosis, CCR5 has been believed to play a greater role in the progression of unstable plaque $(19-21,29)$. In our previous study, we have reported the upregulation of $8 \mathrm{CRs}$, including CCR5-which was one of the most expressed receptors in the wire-injury-induced atherosclerosis model-with a promiscuous tracer ${ }^{64} \mathrm{Cu}$-DOTA-vMIP-II via PET/CT and im-
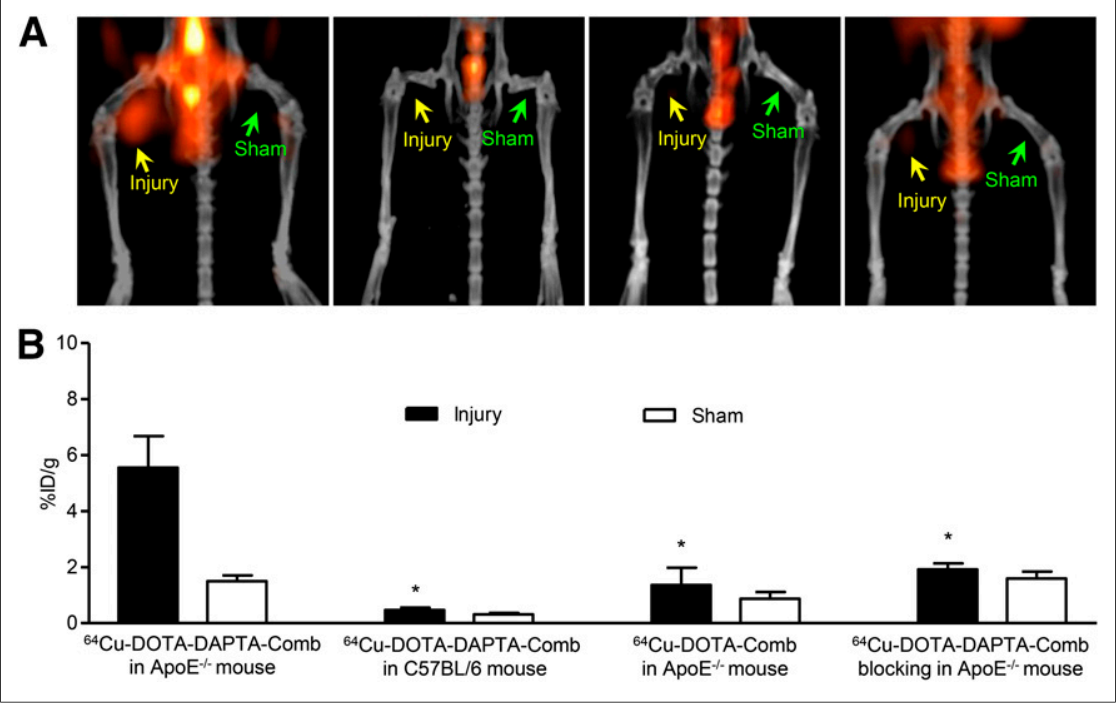

FIGURE 4. (A) Representative 24-h maximum-intensity-projection images of ${ }^{64} \mathrm{Cu}$-DOTADAPTA-comb in $\mathrm{ApoE}^{-/-}$mouse, C57BL/6 mouse, ${ }^{64} \mathrm{Cu}-\mathrm{DOTA}-\mathrm{comb}$ in ApoE ${ }^{-/-}$mouse, and ${ }^{64} \mathrm{Cu}$-DOTA-DAPTA-comb blocking (DOTA-DAPTA-comb to ${ }^{64} \mathrm{Cu}$-DOTA-DAPTA-comb, 100:1) in $\mathrm{ApoE}^{-/-}$mouse at $2 \mathrm{wk}$ after injury. (B) Uptake analysis of corresponding PET images. Quantitative bar graph is below each region of interest. ${ }^{*} P<0.001$, compared with uptake of ${ }^{64} \mathrm{Cu}$ DOTA-DAPTA-comb at the injury lesion in $\mathrm{ApoE}^{-/-}$mouse $(n=6)$. munohistochemistry (22). However, the detection specificity and sensitivity for CCR5 needs to be improved to further explore its pathologic role during the progression of atherosclerosis from early to later stages of the disease. Of the ligands, antagonists, and agonists for CCR5, the DAPTA peptide was selected because of its high binding affinity to the receptor and suitability as a targeting ligand for nanoparticle construction $(24,31)$. As shown in Figure 2, the specific accumulation of ${ }^{64} \mathrm{Cu}$-DOTA-DAPTA at the injured artery was clearly observed. However, its fast pharmacokinetics limited the sensitivity and contrast for CCR5 imaging in vivo, thus making a DAPTA-modified nanoparticle with extended blood circulation a viable candidate for overcoming these difficulties. In related studies, biocompatible poly(methyl methacrylate)core/polyethylene glycol-shell amphophilic nanoparticles have shown the ability in controlled functionalization and poly- 


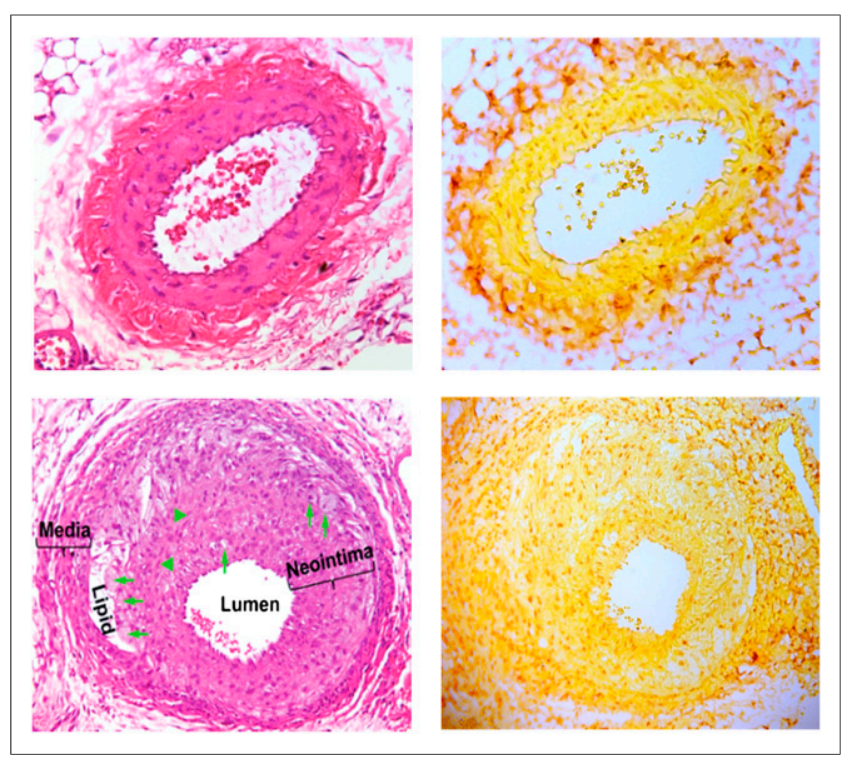

FIGURE 5. Representative H\&E images (left) and DAB images (right) of sham-operated (top) and injured (bottom) femoral arteries from $\mathrm{ApoE}^{-/-}$ mouse at 2 wk after injury. Green arrow = foam cells; green arrowhead = smooth muscle cells; CCR5 = brown; counterstain = yellow.

merization to tailor the biodistribution and targeting efficiency for improved PET/CT imaging in an animal disease model (27). Thus, this nanoplatform was conjugated with DAPTA peptide to afford a DAPTA-comb nanostructure in which $10 \%$ of the PEG chain ends were functionalized with DAPTA $(\sim 14$ per particle) for initial in vivo evaluation.

Previously, we have reported the biodistribution of nontargeting ${ }^{64} \mathrm{Cu}$-DOTA-comb nanoparticles with enhanced blood signal but high mononuclear phagocyte system uptake (27). With the conjugation of DAPTA peptide, the blood signal of ${ }^{64} \mathrm{Cu}$-DOTADAPTA-comb was further extended, with more than $15 \% \mathrm{ID} / \mathrm{g}$ remaining even after $48 \mathrm{~h}$ of circulation in vivo. Although the hepatic and splenic accumulations of ${ }^{64} \mathrm{Cu}$-DOTA-DAPTA-comb slowly increased during the 48-h study, they were still significantly $(P<0.001, n=4)$ lower than those obtained with ${ }^{64} \mathrm{Cu}$-DOTAcomb, reasonably due to the effect of the neutral surface charge ( $\zeta$ potential, DOTA-DAPTA-comb $=6.2 \pm 2 \mathrm{mV}$ vs. DOTAcomb $=-35 \pm 2 \mathrm{mV}$ ), which was consistent with a previous report (27). More importantly, the extended blood signal, in combination with strong binding affinity and high specific activity, required only 1.9 pmol of ${ }^{64} \mathrm{Cu}$-DOTA-DAPTA-comb for in vivo PET imaging. This results in sensitive, specific detection and high contrast for CCR5 in the wire-injured $\mathrm{ApoE}^{-1-}$ mouse model whereas the control ${ }^{64} \mathrm{Cu}$-DOTA-comb showed minimal nonspecific accumulations at injury lesion at a level similar to that accrued at the sham-operated site.

The quantitative uptake analysis showed that ${ }^{64} \mathrm{Cu}$-DOTADAPTA-comb accumulations at the injury lesion were significantly higher than those obtained from the sham site at each time point, with an injury-to-sham uptake ratio as high as 4.4 at the 48 -h time point. Further, it was observed that the ${ }^{64} \mathrm{Cu}$-DOTADAPTA-comb uptake at the injury lesion increased over time during the study, which is reasonably due to the accumulative binding of circulating ${ }^{64} \mathrm{Cu}$-DOTA-DAPTA-comb to CCR5 receptor recycled back to the cell surface after internalization (32). In contrast to ${ }^{64} \mathrm{Cu}$-DOTA-DAPTA, the uptake of ${ }^{64} \mathrm{Cu}$-DOTA-
DAPTA-comb at $1 \mathrm{~h}$ was almost twice as much, most likely due to the enhanced targeting efficiency of ${ }^{64} \mathrm{Cu}$-DOTA-DAPTA-comb with the multi copies of DAPTA per nanoparticle. All of these demonstrated the advantage of a long-circulating nanoparticle for cardiovascular disease imaging. Additionally, the minor but not statistically different increase of ${ }^{64} \mathrm{Cu}$-DOTA-DAPTA-comb uptake at the injury lesion between 24 and $48 \mathrm{~h}$ indicated that the tracer accumulation was mainly mediated through CCR5 receptor binding not the nonspecific accumulation because the remaining ${ }^{64} \mathrm{Cu}-$ DOTA-DAPTA-comb in the blood did not incur any significant nonspecific binding. More importantly, the significant decrease of tracer uptake at the injury lesion via the competitive PET blocking clearly confirmed the targeting specificity of ${ }^{64} \mathrm{Cu}$-DOTA-DAPTAcomb for the CCR5 receptor. Furthermore, the low ${ }^{64} \mathrm{Cu}$-DOTADAPTA-comb uptake in the wire-injured C57BL/6 mice shown in Figure 4A eliminates the concern of nonspecific tracer accumulation due to the surgical procedure and corroborated the targeting specificity. However, one potential limitation of this ${ }^{64} \mathrm{Cu}$-DOTADAPTA-comb for cardiovascular imaging was the high blood signal, which might increase the background signal and lead to a low contrast ratio. One approach is to increase the amount of targeting peptide conjugated on the nanoparticles. It was demonstrated that not only could the blood signal be significantly reduced but also the targeting efficiency of the nanoparticles could be improved $(27,33)$. Further, the optimized imaging probe needs to demonstrate its improved targeting efficiency not only in the wire-injury model, which may be limited by the potential artificial effect during the injury procedure, but also in a model with spontaneously developed lesion.

In addition, $\mathrm{H} \& \mathrm{E}$ staining visibly showed the significant progress of vascular lesions at $2 \mathrm{wk}$ after injury in the $\mathrm{ApoE}^{-1-}$ mice, with typical characteristics found in atherosclerosis, such as foam cell infiltration, lipid deposition throughout the neointima, smooth muscle cell proliferation, and neointima thickening. Immunohistochemistry via DAB staining depicted the upregulation of CCR5 after wire injury, whereas only minimal expression of the receptor was observed in the sham-operated tissue. More importantly, the quantitative RT-PCR showed significantly higher upregulation of CCR5 in the injured arteries than that expressed in the shamoperated vessel, consistent with the PET/CT imaging data. Further, it is known that CCR5 is mostly expressed in multiple subsets of leukocytes including monocytes and neutrophils (19), which affects the progression and rupture of plaques. It will be important to identify the expression profile of CCR5 in these inflammatory cells during the progression of plaque and combine it with the PET imaging results for a comprehensive evaluation of the role of CCR5 in atherosclerosis in the future studies.

\section{CONCLUSION}

In this study, we imaged the expression of the CCR5 receptor with $\mathrm{PET} / \mathrm{CT}$ in a wire-injury-induced $\mathrm{ApoE}^{-/-}$atherosclerosis model using a DAPTA targeting peptide-conjugated nanoparticle of ${ }^{64} \mathrm{Cu}$-DOTA-DAPTA-comb prepared through modular construction with tailored physical and biologic properties. The improved blood signal, high radiolabeling specific activity, and elevated targeting efficiency of amphophilic ${ }^{64} \mathrm{Cu}$-DOTA-DAPTA-comb afforded in vivo imaging capabilities superior to the ${ }^{64} \mathrm{Cu}$-DOTADAPTA peptide alone. The biologic confirmation of the PET image results grants this nanoparticle significant potential as a noninvasive approach for further assessment of the pathologic functions of the CCR5 receptor in animal atherosclerosis models. 


\section{DISCLOSURE}

The costs of publication of this article were defrayed in part by the payment of page charges. Therefore, and solely to indicate fact, this article is hereby marked "advertisement" in accordance with 18 USC section 1734 . This work is supported by the National Heart, Lung and Blood Institute of the National Institutes of Health as a Program of Excellence in Nanotechnology (HHSN268201000046C). The characterization of nanoparticles is performed in the Central Facilities of the UCSB Materials Research Laboratory supported by the MRSEC Program of the National Science Foundation under award no. DMR1121053. No other potential conflict of interest relevant to this article was reported.

\section{ACKNOWLEDGMENTS}

We thank Nicole Fettig, Margaret Morris, Amanda Roth, Lori Strong, and Ann Stroncek for their assistance with animals and imaging studies and Tom Voller, Evelyn Madrid, Paul Eisenbies, Efrem Mebrahtu, and Suzanne Lapi for ${ }^{64} \mathrm{Cu}$ production. We thank the helpful discussion and comments from Professor Dana Abendschein. We would like to dedicate this publication to Professor Michael J. Welch, a leading PET imaging scientist in the world who greatly supported this research until he passed away on May $6,2012$.

\section{REFERENCES}

1. Libby P, Ridker PM, Hansson GK. Inflammation in atherosclerosis: from pathophysiology to practice. J Am Coll Cardiol. 2009;54:2129-2138.

2. Tuttolomondo A, Di Raimondo D, Pecoraro R, Arnao V, Pinto A, Licata G. Atherosclerosis as an inflammatory disease. Curr Pharm Des. 2012;18:4266-4288.

3. Libby P, Ridker PM, Maseri A. Inflammation and atherosclerosis. Circulation. 2002;105:1135-1143.

4. Rudd JH, Hyafil F, Fayad ZA. Inflammation imaging in atherosclerosis. Arterioscler Thromb Vasc Biol. 2009;29:1009-1016.

5. Deguchi JO, Aikawa M, Tung $\mathrm{CH}$, et al. Inflammation in atherosclerosis: visualizing matrix metalloproteinase action in macrophages in vivo. Circulation. 2006;114:55-62.

6. Weber C, Noels H. Atherosclerosis: current pathogenesis and therapeutic options. Nat Med. 2011;17:1410-1422.

7. Choudhury RP, Fisher EA. Molecular imaging in atherosclerosis, thrombosis, and vascular inflammation. Arterioscler Thromb Vasc Biol. 2009;29:983-991.

8. Quillard T, Libby P. Molecular imaging of atherosclerosis for improving diagnostic and therapeutic development. Circ Res. 2012;111:231-244.

9. Perrone-Filardi P, Dellegrottaglie S, Rudd JH, et al. Molecular imaging of atherosclerosis in translational medicine. Eur J Nucl Med Mol Imaging. 2011;38:969-975.

10. Libby P, DiCarli M, Weissleder R. The vascular biology of atherosclerosis and imaging targets. J Nucl Med. 2010;51(suppl 1):33S-37S.

11. Boersma HH, de Haas HJ, Reutelingsperger CP, Slart RH. P-selectin imaging in cardiovascular disease: what you see is what you get? J Nucl Med. 2011; 52:1337-1338.
12. Dimastromatteo J, Broisat A, Perret $\mathrm{P}$, et al. In vivo molecular imaging of atherosclerotic lesions in ApoE-/- mice using VCAM-1-specific, ${ }^{99 \mathrm{~m}} \mathrm{Tc}-\mathrm{la}-$ beled peptidic sequences. J Nucl Med. 2013;54:1442-1449.

13. Rudd JH, Myers KS, Bansilal S, et al. Atherosclerosis inflammation imaging with ${ }^{18}$ F-FDG PET: carotid, iliac, and femoral uptake reproducibility, quantification methods, and recommendations. J Nucl Med. 2008;49:871-878.

14. Zernecke A, Shagdarsuren E, Weber C. Chemokines in atherosclerosis: an update. Arterioscler Thromb Vasc Biol. 2008;28:1897-1908.

15. Charo IF, Ransohoff RM. The many roles of chemokines and chemokine receptors in inflammation. $N$ Engl J Med. 2006;354:610-621.

16. Bursill CA, Channon KM, Greaves DR. The role of chemokines in atherosclerosis: recent evidence from experimental models and population genetics. Curr Opin Lipidol. 2004;15:145-149.

17. White GE, Iqbal AJ, Greaves DR. CC chemokine receptors and chronic inflammation-therapeutic opportunities and pharmacological challenges. Pharmacol Rev. 2013;65:47-89.

18. Tacke F, Alvarez D, Kaplan TJ, et al. Monocyte subsets differentially employ CCR2, CCR5, and CX3CR1 to accumulate within atherosclerotic plaques. J Clin Invest. 2007;117:185-194.

19. Quinones MP, Martinez HG, Jimenez F, et al. CC chemokine receptor 5 influences late-stage atherosclerosis. Atherosclerosis. 2007;195:e92-e103.

20. Jones KL, Maguire JJ, Davenport AP. Chemokine receptor CCR5: from AIDS to atherosclerosis. Br J Pharmacol. 2011;162:1453-1469.

21. Koenen RR, Weber C. Therapeutic targeting of chemokine interactions in atherosclerosis. Nat Rev Drug Discov. 2010;9:141-153.

22. Liu Y, Pierce R, Luehmann HP, Sharp TL, Welch MJ. PET imaging of chemokine receptors in vascular injury-accelerated atherosclerosis. J Nucl Med. 2013;54:1135-1141.

23. Rosi S, Pert CB, Ruff MR, McGann-Gramling K, Wenk GL. Chemokine receptor 5 antagonist D-Ala-peptide T-amide reduces microglia and astrocyte activation within the hippocampus in a neuroinflammatory rat model of Alzheimer's disease. Neuroscience. 2005;134:671-676.

24. Polianova MT, Ruscetti FW, Pert CB, Ruff MR. Chemokine receptor-5 (CCR5) is a receptor for the HIV entry inhibitor peptide T (DAPTA). Antiviral Res. 2005;67:83-92.

25. Liu Y, Welch MJ. Nanoparticles labeled with positron emitting nuclides: advantages, methods, and applications. Bioconjug Chem. 2012;23:671-682.

26. Pressly ED, Rossin R, Hagooly A, et al. Structural effects on the biodistribution and positron emission tomography (PET) imaging of well-defined ${ }^{64} \mathrm{Cu}$-labeled nanoparticles comprised of amphiphilic block graft copolymers. Biomacromolecules. 2007;8:3126-3134.

27. Liu Y, Pressly ED, Abendschein DR, et al. Targeting angiogenesis using a Ctype atrial natriuretic factor-conjugated nanoprobe and PET. J Nucl Med. 2011;52:1956-1963.

28. Westrick RJ, Winn ME, Eitzman DT. Murine models of vascular thrombosis (Eitzman series). Arterioscler Thromb Vasc Biol. 2007;27:2079-2093.

29. Zernecke A, Liehn EA, Gao JL, Kuziel WA, Murphy PM, Weber C. Deficiency in CCR5 but not CCR1 protects against neointima formation in atherosclerosisprone mice: involvement of IL-10. Blood. 2006;107:4240-4243.

30. Zernecke A, Weber C. Chemokines in the vascular inflammatory response of atherosclerosis. Cardiovasc Res. 2010;86:192-201.

31. Ruff MR, Polianova M, Yang QE, Leoung GS, Ruscetti FW, Pert CB. Update on D-ala-peptide T-amide (DAPTA): a viral entry inhibitor that blocks CCR5 chemokine receptors. Curr HIV Res. 2003;1:51-67.

32. Mueller A, Kelly E, Strange PG. Pathways for internalization and recycling of the chemokine receptor CCR5. Blood. 2002;99:785-791.

33. Pressly ED, Pierce RA, Connal LA, Hawker CJ, Liu Y. Nanoparticle PET/CT imaging of natriuretic peptide clearance receptor in prostate cancer. Bioconjug Chem. 2013;24:196-204. 